\title{
FULL TERM SECONDARY ABDOMINAL PREGNANCY
}

\author{
DR. RAHILA FARHAT \\ MBBS, MCPS, FCPS, \\ Gynaecologist,
}

Social Security Hospital Faisalabad

\author{
PROF. DR. MAHNAAZ ROOHI \\ MBBS, MRCOG, FRCOG, \\ Professor and Head of Gynae Department, \\ Allied Hospital/PMC Faisalabad
}

\begin{abstract}
In properly evaluated patients full term abdominal pregnancy can be managed, although advanced abdominal pregnancy is a complex condition demanding challenging management. This care report describes case of a young lady 35 years age who was diagnosed as a case of secondary abdominal pregnancy and was managed successfully.
\end{abstract}

Key Words: $\quad$ Laparotomy, Pregnancy, Ectopic, Abdominal.

\section{INTRODUCTION}

Abdominal pregnancy, a rare variety of ectopic pregnancy is defined as an intra peritoneal implantation exclusive of tubal, ovarian or intra-ligamentous implantation 1 . The world wide incidence ranges from 1:1320 to $1: 10,200$ births $^{1,2}$.

Abdominal pregnancy is of two types:-

\section{Primary Abdominal Pregnancy}

When ovum is implanted directly into peritoneal cavity. It is rare phenomenon with only 24 cases reported in world literature ${ }^{3}$.

\section{Secondary Abdominal Pregnancy}

When pregnancy occurs initially in tube and later on tubal abortion occurs and foetus gets implanted in peritoneal cavity. Secondary abdominal pregnancy is more common. This condition is associated with high maternal mortality with reported rates of .5 to $18 \%{ }^{4}$. The major cause for this is massive hemorrhage which may occur during pregnancy during surgery or in postoperative period. Similarly condition is associated with high peritoneal mortality rate of about $95 \%$.

This is attributed to pre-term deliveries resulting from active intervention done in majority of cases as soon as diagnoses is made.

\section{CASE REPORT}

A middle aged lady presented in emergency labour room of gynae unit I Allied Hospital Faisalabad. She was a case of precious pregnancy conceiving after 14 years of marriage. She was having gestational age of 9 months (not sure of dates). She was having mild labour pains. There was no other significant complaint. On general clinical examination she was pale looking. On abdominal examination abdomen was tense and tender. Her fundal 
height was greater than thirty six weeks. Fetal parts were difficult to palpate but fetal heart was audible. C.T.G was done it was reactive. The provisional diagnoses based on clinical findings was;

\section{Rupture uterus \\ 2. Abruptio placenta}

But the clinical signs were not in favor of any of these provisional diagnosis as her vitals were well maintained and her CTG was reactive. Her base line investigations were within normal limits. U.S.G was done and she was diagnosed as a case of abdominal pregnancy. Blood was arranged and she was prepared for emergency laparotomy. On laparotomy there was a gestational sac outside the uterus. A nick was given in the sac and the baby was delivered with apgar score $6 / 10,4 / 10$. Baby had many compression deformities. Nose forehead and chest were compressed. Baby expired after half an hour. Later the placenta was localized, it was adherent to gut and omentum and so it was left in situ. Drain was placed in pouch of douglas and abdomen closed.

The patient had a remarkable recovery. Her base line beta H.C.G was sent. She was given injection methotrexate $50 \mathrm{mg} / \mathrm{kg}$ weekly. And her serial estimation of beta H.C.G was done. Her beta H.C.G showed a rapid decline within six weeks and her serial U.S.G showed complete resolution of placenta in three months.

\section{DISCUSSION}

The incidence of abdominal pregnancy in Pakistan was found to be $0.04 \%$ of total deliveries and $5.6 \%$ of ectopic pregnancies 5 . The major factor found was non availability of parental care.

It is usually easier to appreciate abdominal pregnancy on U.S.G examination at end of the first trimester when pelvic organs are best visualized. However presentation of cases at an advanced stage poses considerable diagnostic problems. The diagnostic errors in different series has ranged from 50 to $90 \%{ }^{6}$. Infect MRI is a considered a gold standard for diagnosis ${ }^{6}$. A lateral x-ray of abdomen showing fetal parts over lying maternal spine may be help full. Similarly elevated maternal serum alpha feto protein have been associated with abdominal pregnancies esp with more extensive visceral implantation ${ }^{7}$.

There has been some debate in management. The management of abdominal pregnancy diagnosed in first trimester or early second trimester in surgical intervention without delay. However, due to late presentation of cases, the condition may remain un diagnosed untill a viable stage of gestation. The major questions raised are related to timing and mode of delivery. Although no international consensus exists on issue, a conservative approach is proposed in absence of fetal gross malformation, placental implantation remote from upper abdomen, good maternal condition, close management in a tertiary care hospital of the patient previously informed of risks and outcomes ${ }^{8}$. Expectant management has been adopted in potentially viable pregnancies to gain fetal lung maturity. Similarly approach has been adopted in another tertiary care hospital of Pakistan and has produced an alive and healthy fetus ${ }^{9}$. Although an undiagnosed asymptomatic abdominal pregnancies may go to 38 weeks, for diagnosed abdominal pregnancy it is recommended that in absence of complications, laparotomy should be planned at 34 weeks ${ }^{10}$.

Management of placenta in advanced abdominal pregnancy is still a matter of debate. Similarly no consensus exists on management of placenta and each case is managed on individual bases according to intra operative findings. Often placenta separates on its own after delivery of infant. However if it does not separate controversy exists whether it should be removed or left in situ. Massive hemorrhage may occur during its removal. The worst hemorrhage near to catastrophe has been reported by Ramachandran ${ }^{4}$. Leaving the placenta in situ with out attempting its removal is also not free of risks. Maternal morbidity and mortality is significantly higher when placenta is left behind. The follow up of placenta which is left in situ or partially removed is done 


\section{by serial B.H.C.G and sonograms ${ }^{11}$.}

Role of post operative methotrexate is currently controversial. However medicine is still favoured by some in dose of $50 \mathrm{mg} / \mathrm{kg}$ I.M for every three weeks for four cycles in combinations with preoperative arterial ambolization $^{12}$.

\section{REFERENCES}

1. Amanda Cotter MD, Luis Izquiero MD Fernando Heredia MD. Abdominal pregnancy Cotter WWW The Fetus. Net 2002-10-22-11.

2. Opare-Addo HS, Daganus S. Advanced abdominal pregnancy: a study of 13 consecutive cases seen in 1993 and 1994 at Kamfo Anokye Teaching Hospital, Kumasi, Ghana. Afr Reported Health 2000: 4: 28-39.

3. Morita R, Tsusmi O, Kuramochi K, Momoeda M, Yoshikawa $H$, Taketani $Y$, et al. Successfully laparoscopic management of primary abdominal pregnancy. Hun Reprod 1996; 11: 2546-7.

4. Ramachandran K, Kirk P. Massive haemorrhage in a previously undiagnosed abdominal pregnancy presenting for elective cesarean delivery. Can J Anaesth 2004; 51: 57-61.

5. Nasira Tasnim, Ghazala Mehmood. Advanced abdominal pregnancy-A Diagnostic and management Dilemma. An Evidence based report. JCPSP 2005; 15: 493-495.
6. Hall JM, Manning N, Moore NR, Tingey WR, Chamberlain $P$. Antenatal diagnosis of a late abdominal pregnancy using ultrasound and magnetic resonance imaging; $A$ cae report of a successful out come. Ultrasound Obstet Gynaecol; 1996; 7: 289-92.

7. Shumway JB, Green Spon JS, Khouzami AN, Platt LD, Blakenmore KJ. Amniotic fluid alpha-feto proteins and maternal serum alpha-feto protein in abdominal pregnancies; correlation with extent and site of placental implantation and clinical implications. J Matern Fetal Med; 1996; 5: 120-3.

8. Deneke F. Advanced abdominal pregnancy in an Ethiopian mother; A case report. East Afr Med 1997; 74: $535-6$.

9. Rana T, Raana T. Abdominal pregnancy with good maternal and perinatal outcome; a case report. Irn J Med Sci 1999; 16: 47-50.

10. Motazedian S. Term a symptomatic abdominal pregnancy with good maternal and perinatal outcome; a case report. Irn J Med Sci 2000; 25: 76-80.

11. Crabtree KE, Collet B, Kilpatrick SJ. Puerperal presentation of a living abdominal pregnancy. Obstet Gynaecol 1994; 84: 646-8.

12. Rahman J, Berkowitz R, Mitty H, Gaddipati S, Brown B, Nezhat F. Minimally Invasive management of an advanced abdominal pregnancy. Obstet Gynaecol 2004; 103: 1064-8. 